\title{
Comparison of Shared Reading versus Emergent Reading: How the Two Provide Distinct Opportunities for Early Literacy
}

\author{
Stephanie M. Curenton and Symonne Kennedy \\ Rutgers University, New Brunswick, NJ 08901, USA \\ Correspondence should be addressed to Stephanie M. Curenton; curenton@rutgers.edu
}

Received 28 February 2013; Accepted 9 April 2013

Academic Editors: B. W. Baldwin, R. Martens, and M. Recker

Copyright (C) 2013 S. M. Curenton and S. Kennedy. This is an open access article distributed under the Creative Commons Attribution License, which permits unrestricted use, distribution, and reproduction in any medium, provided the original work is properly cited.

\begin{abstract}
This study examined mother-child interactions across two types of reading interactions-shared reading versus emergent readingin order to determine (a) if mothers and children provide the same amount of language input across the two interactions, (b) if the socioemotional quality is consistent across the interactions, and (c) if the language input and socioemotional quality across the two interactions are differentially associated with children's scores on early literacy assessments. Twenty-five mother-child dyads participated in both interactions. Children were given a standardized test of early reading and an emergent reading score based on a rubric designed particularly for the book they were reading. Results indicated that during the shared reading mothers provided more language input (i.e., they talked more), but children increased their amount of talk during the emergent reading, making such input effects null. Overall, socioemotional quality was consistent across the two interactions, except mothers provide more literacy feedback during shared reading. Both language input and socioemotional quality were associated with higher scores on early literacy assessments, but the contribution of these factors varied depending across the type of reading interaction. Results are discussed in terms of education implications for literacy practices at home and school.
\end{abstract}

\section{Introduction}

Before young children can actually read, they possess a body of knowledge pertaining to reading and writing that teachers, developmental psychologists, and researchers refer to as early literacy skills. These skills include meaning-based and code-based skills related to vocabulary, morphosyntax, listening comprehension, print awareness, and phonological awareness (for a detailed discussion of skills see [1]). Early literacy skills are developed through repeated exposure to language and literacy activities at school and home, and two of the activities we explore in this study are typical shared reading and emergent reading. In this study, typical shared reading between a parent and child is characterized by a one-on-one interaction in which an adult reads a story to the child and encourages the child to be actively involved by asking questions and allowing him/her to share their ideas and opinions about the story. In comparison, we define emergent reading as a one-on-one interaction between a parent and child in which a child uses the pictures of book, along with what they remember about that book, to retell the story perhaps with guidance from the parent in the form of questions and encouragement. Both typical shared reading and emergent reading have been shown to be significant predictors of children's later literacy skills, namely their reading and narrative comprehension [2-7].

Work by Kaderavek and Sulzby [8] has compared emergent readings and oral narratives, but to date, no study has compared typical shared versus emergent readings in terms of how parent-child interaction might differ across the two reading contexts, specifically as it relates to the language input provided by each participant, how the socioemotional quality of the interaction might vary across the readings, and how the two might be uniquely related to children's early literacy skills. The purpose of this small-scale descriptive study was to compare these two reading interactions and to provide evidence of the quantitative and qualitative differences between the two interactions. 


\section{Shared Reading versus Emergent Reading}

Both in shared and emergent reading interactions parents are able to cater to the interests and developmental needs of the child, and by doing so the parent is attempting to make the interaction enjoyable as well as educational [5]. Prior research indicates that mothers who have positive views of shared reading (e.g., mothers who believe reading interactions should be educational, enjoyable activities in which the child is actively engaged) have children with better literacy skills [9]. Therefore, we know that the socioemotional quality of the interaction is an important factor to consider when studying reading interactions. The question posed by this study is whether the socioemotional quality would be the same across the two reading interactions. One could hypothesize that the quality would be better during the emergent reading versus the shared reading given that during the emergent reading the child is the main "storyteller," which provides many opportunities for mothers to provide praise and encourage children's nascent literacy skills.

Another important aspect to investigate is the language input across the two interactions. One fundamental goal during reading interactions is to engage children in a dialogue around a text. In fact, there is a well-known body of research confirming that if parents and teachers are properly trained to use specific dialogic techniques there will be gains in children's literacy skills [10-12]. Although there is literature on such specific intervention programs, the field still needs information about the language input parents and children provide naturally without intervention training, especially during those instances like emergent reading, when the child is taking the lead in telling the story. To our knowledge, only a few studies have contrasted emergent reading with other narrative/storytelling interactions. Kaderavek and Sulzby [8] in their comparison of emergent reading with oral narrative production provide some evidence that children do indeed provide different language input across these two narrative contexts. For example, they found that children's language input was better during the emergent reading narratives versus the oral storytelling narratives: Children's emergent reading narratives included a greater number of utterances and utterances that were more grammatically complex, and children were more likely to use literate language features, such as reported speech and character dialogue. Their study provides detailed information about how children's language input is different across context, but there is still a gap in the knowledge regarding how mothers' language input might be different when comparing emergent reading with shared reading interactions. The work of Curenton et al. [13] is a study in which emergent reading was actually compared to shared reading, and their results indicated that although mothers talked more and used more grammatically complex talk than children during shared reading, there were no differences between the mothers' and children's talk during emergent reading. Lastly, Martin-Chang and Gould [14] compared mother's language input across the reading interactions of shared-reading (when the mother read to the child) and a child's reading (when the child actually "read" to the mother), and they found mothers focused more on the text when the child was reading to her but more on the illustrations when she was reading to the child. Thus, in these situations in which children are actually "readers," mothers' input changes from being meaning-based focused to code-based focused; other researchers have found similar results during parent-child interactions with first graders [15].

In sum, these prior studies indicate that there is something special about emergent reading compared to other storytelling/reading interactions in that children demonstrate better skills during emergent reading than they do during other storytelling interactions [8] and that children are able to converse at a level equivalent to that of their mothers when they are engaged in emergent reading versus other types of narrative interactions [13]. Such findings lead one to hypothesize that children will produce more language input during the emergent reading versus the shared reading interactions in the current study.

Finally, there is a need for more research that compares reading interactions in terms of how they are related to children's literacy outcomes. One study has addressed such a comparison among teachers. In the work of Lonigan et al., [12] they trained research assistants to deliver dialogic reading and typical shared reading in preschool classrooms with small groups of children; they concluded that both reading interactions have overall positive effects on children's literacy skills but that shared reading had more favorable effects on children's listening comprehension and their phonological awareness. Lonigan and colleague's study provides important information about the outcomes associated with the two types of readings in their study, but it does not provide information about how shared reading might compare with emergent reading. Given the prior results from Lonigan et al's study, it would be difficult to hypothesize whether shared versus emergent reading would have stronger associations with children's early reading skills since their research says that both are effective. Therefore, we propose no a priori hypothesis for the association with early literacy outcomes.

\section{Present Study}

The purpose of this small-scale descriptive qualitative study was to compare mother-child dyads engaged in a shared reading versus an emergent reading interaction in order to investigate if the mothers and children behaved differently in terms of the their language input during the interactions (i.e., the number of utterances, the mean length of the utterance [MLU], and number of questions) and whether the socioemotional quality of the interaction is different across the two interactions. We also investigated which of these language and socioemotional aspects of the emergent versus the shared reading are more strongly associated with children's concurrent early literacy skills, as measured by performance on a standardized test of early literacy as well as an emergent reading task. 


\section{Method}

4.1. Participants. The sample consisted of 25 mother-child dyads with 12 boys and 13 girls. Children in these dyads ranged from 37-63 months old $(M=50.96$ months, $\mathrm{SD}=$ $8.33)$. The racial breakdown of the sample was such that 16 of the children were black (64\%), 7 were white $(28 \%)$, 1 child was Latino (4\%), and 2 children were Asian/Native American/Biracial (4\%). In terms of general language ability, all the children were in the normative range of two-standard deviations from the mean as evidenced by Peabody Picture Vocabulary Test (PPVT-III; [17]) scores of $M=101.67$ (SD = 8.81 , range $80-124)$.

The ages of the mothers in the sample ranged from 23 to 41 years old $(M=30.60$ years, $\mathrm{SD}=5.04)$. Most of the parents in these dyads either had a bachelor's Degree or went to graduate school (68\% of sample), while the rest of the parents had at least some college level education or went to trade/vocational school beyond high school (24\%). All but one of the mothers reported that they were currently working for pay. Mothers, on average, were very literate as indicated by Wide Range Achievement Test (WRAT3; [18]) reading scores equivalent to either high school or post-high school level, which are among the highest literacy levels for the test $(M=107.20, \mathrm{SD}=8.21$, range of 92-118). In terms of income, the sample was primarily middle class, with the majority of mothers reporting that their annual income was on average between $\$ 40,000$ and $\$ 50,000$. To further assess the income level of the families, an income-toneeds ratio was created by dividing income by the poverty guideline for family size. The range of the income-to-needs ratio was from 1 to 5 with a mean of 2.77 ( $\mathrm{SD}=1.09, N=$ 21). Any ratio greater than 1.8 is above poverty. There were only 4 mothers whose income-to-needs ratio placed them as being at/below (ratios $<1.0$ ) or near poverty (ration $>$ 1.0 to 1.8 ). This ratio has been widely used in other studies to assess family SES (see [19-21]) and has been used as an eligibility indicator for federal and state public assistance programs.

4.2. Procedure. Families were recruited via letter and inperson sign-ups at their child's preschool or child care facility. Parents who agreed to participate were then scheduled for a 60-minute "family visit" within a laboratory setting at a communications disorder department on a southern university campus. A group of ethnically diverse research assistants interviewed children and mothers separately for the first portion of the visit (approximately 45-50 minutes), and during the last portion of the visit (approximately 10-15 minutes) the dyad was brought together to be videotaped engaging in the reading interactions in an observation room setup like a living room with a camera that was visible. During the separate children's portion of the visit, assessments of children's language (i.e., PPVT-III) and literacy skills were administered, and the interviewer read The Snowy Day [16] to children. During the separate parent portion of the visit, information about the family background and mother's literacy was taken. All data about the interaction quality were based on ratings of the dyad during the reading interaction; these ratings were conducted by the new research assistants who had not been involved in data collection and took place once the entire data collection period was completed.

4.2.1. Reading Interactions. This study focuses on the first two reading interactions from Curenton et al. [13]. Parents were presented with two books and instructed to allow their child to "pretend" to read The Snowy Day book that had just previously been read to them and then to read Peter's Chair [22] to their child. Parents were told to read to their child the way they normally would and to make themselves feel comfortable. They were reassured there was no right or wrong way to do this and that the purpose was to get a sense of what the dyad normally did when they read together.

The Snowy Day is a story about a boy's adventures in the snow; while the character is out playing in the snow, he makes a snow angel, drags a stick through the snow to make a track, avoids a snowball fight, and makes a snow ball that eventually melts in his pocket. This is a popular children's book that has been used in various other studies to assess children's narrative abilities [23-25]. Peter's Chair is about a boy who struggles to accept the birth of his younger sister. The plot provides opportunities for mothers to make comments about emotions (e.g., by talking about Peter's feelings of anger and jealousy), misbehavior (e.g., Peter's decision to take his belongings and run away), and resolution (e.g., when Peter decides to allow his furniture to be passed down to his younger sister). This book has also been used in other studies that examined children's narrative skills [24]. Peter is the main character in both of the books. The Snowy Day reading is hereafter referred to as the emergent reading, and Peter's Chair is hereafter referred to as the shared reading. There were a total of 25 emergent reading interactions and 24 shared reading interactions.

4.2.2. Transcription. Two graduate level research assistants first individually transcribed the interactions verbatim into the child language analysis (CLAN) program [26]; then they each independently listened to the tapes and checked each other's transcriptions for accuracy. Corrections to the transcript were made when discrepancies were observed. After the interactions were transcribed and checked for accuracy, the first author and a graduate assistant deleted repetitions, irrelevant remarks (e.g., questions to the experimenter about the procedures, repetitions within utterances, filler words, and comments not related to the story), and as well as any of the mother's comments that were verbatim readings of the text for the shared reading (see [27]). Interrater reliability for the deletion procedure was determined for $12 \%$ ( $n=$ total of 6 (3 per reading interaction) out of 49 ) of the transcripts and was calculated by dividing the total number of agreements by the total number of item comparisons and multiplying by 100 . For the shared reading, the interrater reliability averaged 93\% (ranging from 91\% to 95\%) and interrater reliability averaged $96 \%$ (ranging from $89 \%$ to $100 \%$ ) for the emergent reading. Disagreements were resolved through discussion. 
TABLE 1: Emergent reading rubric for The Snowy Day [16].

\begin{tabular}{llc}
\hline Item number & Item description & Scoring (total possible = 7) \\
\hline 1 & Says words that are actually on the page & 01 (at least 50\% of time) \\
2 & Produces an accurate portrayal of events on the current page & 01 (at least 50\% of time) \\
3 & Mentions internal thoughts and/or feelings of character & 01 (at least one mention) \\
4 & Comment illustrating their memory/understanding that a stick made & 01 \\
& a third set of track & Comment illustrating their memory/understanding that Peter is \\
5 & younger/smaller than the other boys playing in the snowball fight & 01 \\
6 & Comment illustrating their memory/understanding that Peter's snowball & \\
7 & melts in his pocket or is "gone" &
\end{tabular}

\subsection{Measures}

4.3.1. Language Input. Utterances within the transcript were segmented into communication units (C-units; [28]). The guidelines for segmenting the narratives are described by Curenton and Lucas [29]. Typically, a C-unit must adhere to a clausal structure, meaning it must contain a subject and a verb. Given that the story interactions take place in the form of a conversation and that people sometimes do not adhere to a clausal structure when speaking in a conversation, allowances were made for including utterances that did not follow a clausal structure yet contained key information about the story or the story interaction. Inter rater reliability $(n=3$ per reading interaction) averaged 93\% (ranging from $91 \%$ to 95\%) for shared reading and 96\% (ranging from 92\% to $100 \%$ ) for emergent reading. All disagreements were resolved via conferencing. CLAN was then used to calculate the number of utterances and the mean length of utterance (MLU) for the mother and child, resulting in an individual score for each across the two reading interactions.

4.3.2. Questions. Questions were coded by hand by the first author, and this consisted of a two-step process. First, the transcripts were scanned for all interrogative statements, next each interrogative statement was scrutinized to evaluate whether it was a question that related to the specific content of the book. Only those questions that were specifically related to the content of the book, or a related conversation around the book, were counted as true questions. Any questions related to the procedure/flow of the task (e.g., "Will you let me read this book to you? Are you listening?") or questions used simply to maintain the flow of the interaction (e.g., "Huh? Hmm?") were not counted. Questions related to managing children's behavior during the task or questions about the experimental procedure (e.g., "What is that camera for?") were not counted either. The total number of questions that were specifically related to the book or a conversation pertaining to the book were summed, resulting in four scores: total number of mother's questions for shared reading $(M=$ $9.17, \mathrm{SD}=7.46$, range $=0-38)$, total number of child's questions for shared reading $(M=2.53, \mathrm{SD}=4.12$, range $=$ $0-16)$, total number of mother's questions for emergent reading
$(M=13.32, \mathrm{SD}=10.64$, range $=1-37)$, and total number of child's questions for emergent reading $(M=1.16, \mathrm{SD}=1.55$, range $=0-5$ ).

4.3.3. Early Reading Scores. Each child's early reading abilities were assessed using the Test of Early Reading Ability-Third Edition (TERA-3; [30]). Only 20 children in the sample were assessed using TERA-3 because five of the children within our sample fell below the age cut-off of 3 years, 6 months for the assessment. The average TERA-3 score was 100.80 $(\mathrm{SD}=11.70$, range $=76-119)$. Based on the interpretation of the TERA-3 reading quotients presented in the manual ( $p$. 26), our sample was broken down into 16 children who had average/above average scores and 4 children who had below average/poor reading scores. Therefore, there was variation across the sample in terms of children's reading scores.

4.3.4. Emergent Reading Score. Successful emergent reading strategies include accurately describing the pictures, using vocabulary or phrases from the book, describing key events from the book, and incorporating prior knowledge and experience (see $[5,31,32]$ ). An emergent reading rubric modified from Valencia and Sulzby's [33] rubric, but also based on the strategies Elster [31], Sulzby, and colleagues [5] described, was developed to assess children's level of success at emergent reading. The items for the rubric along with their scoring criteria are detailed in Table 1. Items on the rubric included whether children used any of the actual vocabulary words from the text, whether they accurately described key events in the story (i.e., items 4-6 that refer to the action landscape of the story (see [34])), whether they made any reference to Peter's thoughts or feelings (e.g., what Curenton [34] would refer to as the consciousness landscape of the story), and whether they used certain key phrases common during reading a story (e.g., "once upon a time" or "the end"). Items 4,5 , and 6 were scored in relation to the content of the present page, meaning in order to receive credit for an item the child must be reading from the page in which the event occurred. The emergent reading score ranged from a possible 0 to 7 points with higher scores indicating that children had better emergent reading skills $(M=3.44, \mathrm{SD}=$ 2.50 , range of $0-7)$. Cronbach's alpha for the scale was .85 . 
Furthermore, there was a significant correlation between children's age and their performance on this measure $(r=.81$, $P<.001$ ), which indicates the scale can consistently assess age-related developmental progress, and between children's performance on this measure and their scores on the standardized TERA-3 $(r=.45, P<.05)$.

4.3.5. Socioemotional Quality. Five qualitative ratings for each reading interaction were used to characterize socioemotional quality. The ratings were based on categorical scores consisting of 1, 3, or 5. Examples of these ratings are included in Table 2. Three of these codes rated the mothers' behavior during the interaction, literacy feedback, balanced control, and redirection, and two of the codes rated children's behavior, task orientation and compliance. A trained undergraduate research assistant coded all of the interactions from the videotapes, and the first author double-coded $12 \%$ of the videotapes ( $n=3$ per interaction) to check for interrater reliability. Interrater reliability was assessed based on the total percentage of point-by-point agreement for each rating and was $94 \%$. Cronbach's alpha for these ratings was $\alpha=.84$ across all the ratings.

\section{Results}

5.1. Differences in Language Input. In order to answer the questions regarding differences in language input paired samples $t$-test were performed on the log transformed (The $\log$ transformation of these values was used in the analyses because the variables were not normally distributed.) values for mothers' and children's language input across the reading interactions. Results for these analyses are described in Table 3, and they indicate that, as expected, mothers talked more than children (i.e., used more utterances), used more complex grammar (i.e., had longer MLUs), and asked more questions than their children during the shared-reading. However, during the emergent reading, although mothers still asked more questions than children, they did not talk more, and there was a trend (To avoid inflating Type I error associated with conducting multiple $t$-tests, the $P$ value .05 was divided by the number of $t$-test conducted (i.e., 6), resulting in an acceptable $P$ value of .008 for significance of each test) for children to use more complex grammar during the emergent reading.

An interesting post hoc, qualitative aspect to describe is the type of questions mothers asked across the two readings. Mothers were more likely to ask questions that required high-level reasoning during the shared reading versus the emergent reading. For example, in dyad A, four (out of seven) thought-provoking questions between a mother and her 5year-old son during the shared reading were, for example, "So why do you think [Peter] wants to run away?" and "Why do you think [his mother] thought that?", compared to only one (out of four) thought-provoking questions during the emergent reading, "You remember when we made snow angels?" Another example from dyad B between a mother and her 3-year-old daughter shows that the level of the questioning even varied for the children; during the shared reading, the child asked four (out of ten) why questions (e.g., "Why he run away?" and "Why is his mom being mean?") compared to zero questions during the emergent reading. Thus, such qualitative examples show that shared reading has an advantage over emergent reading when it comes to using questions that promote higher-level reasoning.

5.2. Differences in Socioemotional Quality. In order to answer the question of whether or not the socioemotional quality of the interaction differed across the two reading, Friedman's tests were conducted for each interaction rating, again correcting for Type I error with a corrected $P$ value of .01. A Friedman's test was chosen as the analytic method because the socioemotional ratings represent repeated-measures nonparametric ordinal data. The test comparing median differences in literacy feedback across the two readings was significant $\left(\chi^{2}=6.40, N=22, P=.011\right.$, Kendall's $W=$ .29), indicating that mothers provided higher-quality literacy feedback during the shared reading than they did during the emergent reading. All the other aspects of socioemotional quality remained consistent across the two readings, and the data in Table 4 illustrate the categories in which the majority of the dyads were rated.

5.3. Associations with Early Literacy Skills. For this study, two tests of early literacy skills were administered; one was the standardized TERA-3, and the other was the emergent reading score created by the authors and based on children's reading of The Snowy Day. Interestingly, none of the language input variables were associated with children's TERA3 scores, but socioemotional ratings during The Snowy Day such as balanced control (Spearman's $r=.50, P=.025, N=$ 20 ) and literacy feedback (Spearman's $r=.45, P=.048, N=$ $20)$ were positively associated with children's performance on this test.

As expected, because the emergent reading score was based on children's performance during the interaction, there were several significant associations between that test and the language input and socioemotional quality during the emergent reading interaction. For example, number of children's utterances (Pearson's $r=.64, P=.001, N=25$ ) and children's $M L U$ (Pearson's $r=.75, P<.001, N=25$ ) was associated with their emergent reading scores. There were also several socioemotional quality ratings associated with children's performance, such as mother's balanced control (Spearman $r=.58, P=.004, N=23$ ) and children's task orientation (Spearman $r=.52, P=.011, N=23$ ) and compliance (Spearman $r=.59, P=.003, N=23$ ).

\section{Discussion}

The purpose of this small-scale, descriptive study was to examine the quality of mother-child interactions across two types of reading interactions-shared reading versus emergent reading - in order to determine (a) if mothers and children provide the same amount of language input across the two interactions, (b) if the socioemotional quality is consistent across the interactions, and (c) if the language 
TABLE 2: Socioemotional Quality Ratings.

(a) MOTHER'S RATINGS

Literacy feedback

Rating 5: When watching this mother, you get the sense that she is trying to "extend" her child's understanding of the book by interpreting the book (e.g., the child says, "He's riding in a blue car," and the mom responds, "Yes, he is. Our car is blue too." or "Yes, he is. What color is our car?") or by explaining the book content for parts they think may be unclear to the child (e.g., "That's a snowball" or "He is trying to sit in that little chair"). These mothers provide high-level feedback/elaboration to the questions and/or comments the children pose. Examples of high-level feedback include talking about the book after reading it, asking open-ended questions that prompt the child to predict what is going to happen, or making connections between the book and real life experiences.

Rating 3: These mothers do not explain or interpret the book. Instead, they might simply repeat what the child had said without extending or elaborating his/her comments at all (e.g., The child says, "He's riding in a blue car," and the mom responds, "Yes, he is riding in a blue car, isn't he?"). These mothers provide low-level feedback/elaboration. Examples of low-level feedback are asking yes/no questions and/or closed-ended questions that prompt the child to label/locate pictures in the book.

Rating 1: These mothers do not ask questions or make comments, and they do not respond to the child's comments about the book. These mothers do not provide any literacy feedback/elaboration during the interaction. They seem to be passively participating in the interaction. They may even seem to be ignoring the child (i.e., the child's interest and/or comments about the book.

\section{Balanced control}

Rating 5: These mothers foster a balanced interaction because both the mother and child are equally contributing to the pace and agenda. There is the sense of a back-and-forth and turn-taking about the interaction.

Rating 3: These mothers are in control of the interaction. There is a sense of drill about this interaction (e.g., the mother asks a question; then the child responds; then the mother asks a question; then the child responds).

Rating 1: These mothers allow the child to set the pace and agenda of the task. These mothers seem to be passive observers during the interaction.

\section{Redirection}

Rating 5: These mothers use a variety of redirection techniques when the child becomes distracted. For example, they may redirect the child by drawing his/her attention to the book (e.g., "Oh, look what happened now.") or by gentle directives that help the child direct their attention (e.g., "Listen, listen." or "Look, at this page.")

Rating 3: These mothers use criticism ("You are not being nice because you don't want to read"). This criticism can be done in a blatant and harsh manner or in a polite, sarcastic tone. These mothers may also use verbal discipline ("Sit down!") or physical discipline to redirect the child (e.g., picking the child up and sitting him down if he walks away or by grabbing the child's arm to make her turn around).

Rating 1: These mothers do not attempt to redirect their child; she does not employ any type of redirection strategies. These mothers do not attempt to manage the child's behavior (e.g., they might ignore misbehavior or the child's distraction).

\section{(b) CHILDREN'S RATINGS}

\section{Task orientation}

Rating 5: These children are interested in reading. They are on task. Markers of being on task include concentrating on the book and/or responding to the mother's comments and questions. These children are looking at the book.

Rating 3: They sometimes seem disinterested in reading. These children are distracted. Markers of distraction are looking at the camera repeatedly or fidgeting. These children might be trying to stay on tasks, but it is hard for them to maintain concentration. These children sometimes look at the book and sometimes look away.

Rating 1: These children may refuse to become involved in the reading. These children are completely off task. Signs of being off task include getting up and moving around during the interaction or playing with a toy. These children never become focused on the task. These children are not looking at the book; instead, they are actively looking away.

\section{Compliance}

Rating 5: These children openly accept help from their mothers (e.g., turning the pages or holding the book together). When watching the dyad, you get the sense that the child is cooperating with the mother.

Rating 3: These children inconsistently accept help from the mother. Sometimes they accept her help, but other times they reject it. When watching this dyad, you get the sense that they are engaged in a tug-of-war or power struggle.

Rating 1: These children do not welcome help from the mother. These children may even be disobedient, aggressive, or whiny. When watching this dyad, you get the sense he/she is avoiding interacting with his/her mother.

input and socioemotional quality during the interactions is differentially associated with children's scores on early literacy assessments. In this study, shared reading was defined as a book reading interaction in which the mother was instructed to read a relatively unfamiliar children's book the way that she "normally" would with her preschooler; almost all of these interactions took the form of the mother reading the story and asking the child questions as she was reading. On the other hand, for the emergent reading the mother was instructed to allow her child to "pretend to read" to her using a book that a research assistant had just previously read to the child; the tone of these emergent reading interactions 
TABLE 3: Descriptive statistics for language input variables across reading interaction conditions.

\begin{tabular}{|c|c|c|c|c|}
\hline & $M$ & SD & $r^{\mathrm{B}}$ & $t$ value $^{\mathrm{B}}$ \\
\hline \multicolumn{5}{|c|}{ Shared reading $(N=24)$} \\
\hline Mother's number of utterances & 49.75 & 31.78 & \multirow{2}{*}{$.84^{* * *}$} & \multirow{2}{*}{$10.22^{* * *}$} \\
\hline Child's number of utterances & 19.54 & 11.99 & & \\
\hline Mother's MLU ${ }^{A}$ & 3.89 & .69 & \multirow{2}{*}{-.04} & \multirow{2}{*}{$4.96^{* * *}$} \\
\hline Child's MLU & 2.61 & 1.09 & & \\
\hline Mother's number of questions & 9.17 & 7.45 & \multirow{2}{*}{.26} & \multirow{2}{*}{$6.52^{* * *}$} \\
\hline Child's number of questions & 2.58 & 4.12 & & \\
\hline \multicolumn{5}{|c|}{ Emergent reading $(N=25)$} \\
\hline Mother's number of utterances & 46.72 & 26.64 & \multirow{2}{*}{.01} & \multirow{2}{*}{1.06} \\
\hline Child's number of utterances & 38.36 & 15.88 & & \\
\hline Mother's MLU ${ }^{A}$ & 3.38 & .86 & \multirow{2}{*}{-.29} & \multirow{2}{*}{$-2.17^{* *}$} \\
\hline Child's MLUA & 4.32 & 1.52 & & \\
\hline Mother's number of questions & 13.32 & 10.64 & \multirow{2}{*}{.18} & \multirow{2}{*}{$8.92^{* * *}$} \\
\hline Child's number of questions & 1.16 & 1.55 & & \\
\hline
\end{tabular}

Note: ${ }^{\mathrm{A}} \mathrm{MLU}$ : mean length of utterance; ${ }^{\mathrm{B}}$ t-tests and Pearson correlations were conducted using the log transformation of language input variables. ${ }^{* * *} P<.001,{ }^{* *} P<.05$.

TABLE 4: Percentage (number of dyads) of socioemotional quality ratings across reading interactions $(N=23)$.

\begin{tabular}{|c|c|c|c|}
\hline & Rating 5 & Rating 3 & Rating 1 \\
\hline \multicolumn{4}{|c|}{ Shared reading } \\
\hline Mother's literacy feedback & $65 \%(8)$ & $35 \%(15)$ & - \\
\hline Mother's balanced control & $78 \%(18)$ & $17 \%(4)$ & $4 \%(1)$ \\
\hline Mother's redirection & $78 \%(18)$ & $22 \%(5)$ & - \\
\hline Child's task orientation & $74 \%(17)$ & $22 \%(5)$ & $4 \%(1)$ \\
\hline Child's compliance & $83 \%(19)$ & $13 \%(3)$ & $4 \%(1)$ \\
\hline \multicolumn{4}{|c|}{ Emergent reading } \\
\hline Mother's literacy feedback & $26 \%(6)$ & $70 \%(16)$ & $4 \%(1)$ \\
\hline Mother's balanced control & $78 \%(18)$ & $4 \%(1)$ & $17 \%(4)$ \\
\hline Mother's redirection & $74 \%(23)$ & $26 \%(6)$ & - \\
\hline Child's task orientation & $61 \%(14)$ & $26 \%(6)$ & $13 \%(3)$ \\
\hline Child's compliance & $78 \%(18)$ & $9 \%(2)$ & $13 \%(3)$ \\
\hline
\end{tabular}

Note: All percentages may not add to 100 due to rounding error.

was quite different in that mothers encouraged children to tell the story by frequently asking the child to describe what had happened on a particular page. Across all of the emergent readings, only one mother actually read from the text of the book, and even when she did it was just for one page.

Therefore, shared reading interactions can be qualitatively described as the typical shared reading interaction in which the mother reads from the text and creates a dialogue around the book. In contrast, the emergent reading can be described as a nontraditional reading in which the mother allows the child to create the story using the pictures in the book and shapes her dialogue around the information the child provides. It is no mistake that mothers interpreted their role during the two interactions quite differently, and there was a systematic difference between the language input and socioemotional quality that was provided during the interactions. In addition, we found that different aspects of the interactions were associated with children's performance on early literacy tests. Each of these results is discussed in turn.

6.1. Language Input. Results indicated that during the shared reading interaction mothers took on the common role of "leading" the interaction in that she talked more, spoke in a more grammatically complex manner than the children, and asked more questions. These results are contrasted with those found during the emergent reading. During the emergent reading, a null result indicated that no significant difference existed between how much mothers and children talked. It is evident when comparing the means for the number of utterances that these null results were not a matter of mothers talking less during the emergent reading interactions but instead were a matter of children talking more. Children talked 50\% more during the emergent reading than they did during the shared reading. Mothers did continue to ask more questions during the emergent reading, but the grammatical complexity of children's talk during the emergent reading increased because children started to speak using longer utterances. Overall, these changes in children's language input suggest that children are actually attempting to "craft" a story during the emergent reading. A qualitative example from dyad $\mathrm{C}$ when a 4-year-old girl engages in emergent reading is presented in the appendix.

6.2. Socioemotional Quality. Although we had hypothesized that there were would be differences in terms of the socioemotional quality of the interaction, the results did not support this hypothesis. In fact, the quality of the interactions remained quite consistent across the two readings, and overall these interactions can be described as high quality. The majority of dyads were categorized as providing Literacy Feedback that would extend a child's knowledge and as having an interaction that was "balanced," meaning that the dyad engaged in productive turn taking. Most of the mothers used a variety of redirection techniques when children became distracted, but in general, the majority of the children were on task and compliant during both of the readings.

The only socioemotional rating that varied was the amount of literacy feedback that mothers provided. During the shared reading, mothers provided more high-level feedback about the book compared to during the emergent reading when she switched her feedback to more low level, such as prompting the child to focus on the pictures to tell the story. This change in literacy feedback is a natural adjustment that mothers made in response to the task: children were tasked with using the pictures to tell a story, and therefore, many mothers focused on trying to direct their child's attention to these stimuli. Otherwise, the way in which mothers managed the interaction and children's behavior remained the same despite the demands of the task. The fact that all of the other aspects of the socioemotional quality remained consistent is actually a positive testament that indicates children were engaged and eager to participate in both reading interactions. 
6.3. Association with Children's Early Literacy. Correlations were conducted to investigate whether there was an association between children's performance on tests of early reading skills and the dyad's behavior during the interaction. In terms of the standardized assessment of early reading results indicated that children from dyads that display higher categories of balanced control and literacy feedback had higher TERA-3 scores. Interestingly, none of the language input variables were associated with children's TERA-3 scores.

On the contrary, using the emergent reading score as an early literacy assessment, showed there were several aspects of the child's language input and socioemotional behavior during the emergent reading that were positively associated with their scores. For instance, children who talked more and used more complex grammar had higher scores on emergent reading. Also, those children who were rated as being more compliant and on task had higher emergent reading scores. Similarly, as was found with the TERA, the way the mother balanced control during the interaction was associated with children's emergent reading score, meaning that dyads that were classified in the higher category of balanced control had children who scored higher on emergent reading. Although preliminary due to the small sample size, such correlations provide promise in our understanding of the importance of observing children's language input and socioemotional behavior during reading interactions. The important aspect to observe in terms of mothers' socioemotional behaviors seems to be how she manages to share control of the reading interaction with her child and the quality of her literacy feedback.

6.4. Research Contributions. This work makes a significant contribution to the literature because it is the first study to use a primarily middle-class African American sample to investigate how mothers and children navigate two different types of reading interactions. It is important to study the language and literacy development of ethnically and socioeconomically diverse children, particularly middle-class African Americans, because the majority of the knowledge base around African American children's development confounds ethnicity and socioeconomic status (see [35-37]). The sampling in this study will contribute to the body of literature on African American children's language and literacy development in which ethnicity and socioeconomic status are not confounded. Another contribution of this work is the detailed quantitative comparison and post hoc qualitative descriptions of the shared reading and emergent reading interactions. Although emergent reading is a popular education practice used both at home and school, no studies have actually examined how it might differ from shared reading.

Despite these important contributions, there were several limitations to the current work. The first limitation concerns the modest sample size $(N=25)$ which was due to the labor intensive nature of repeated transcription and coding across the two reading conditions. However, prior seminal studies that contrasted emergent reading with oral narratives had a similar sample size (see [8]); therefore, we know that reliable and meaningful results can be obtained with such a sample size.

6.5. Educational Implications. Although much of the education policy suggestions emphasize the importance of parents reading to their children, this work indicates that there may also be promise in amending these suggestions to encourage parents to allow their young children to "read" to them as well. This suggestion is especially important given that our data show that children talk more during these interactions. Therefore, emergent readings may provide an opportunity for children to shine as story tellers and to practice their expressive language skills as well as stay engaged.

\section{Appendix}

\section{Emergent Reading of Snowy Day [16] from a 4-Year-Old Girl}

( $C=$ Child, $M=$ Mother). In certain places the transcript has been modified to for clarity of presentation; the transcript is broken down by pages in order to facilitate the reader's understanding of the child's narrative and to see how her story lines up with the events from the book is taken from a 51 months old who attended private child care in a small southern city. She lived in a middle-class family with an average annual income of \$75,000, and her mother had a bachelor's degree and worked as an insurance specialist. The daughter had average language abilities (PPVT-III score = 99; TERA-3 $=104$ ) as measured by standardized assessments.

Title Page

C: The Snowy Day. [Repeats the title.] The Snowy Day. M: Good.

Page 1

C: One day I woke up and everything [restarts], the snow had fallen on everything.

Page 2

C: And I put on my snow shoes. And I went outside to play.

M: Oh! [Mom acts surprised and excited about the child's story].

C: And I had a xxx [word could not be heard clearly].

$\mathrm{M}: \mathrm{Hmmm}$ ?

Page 3-4

C: And him saw footprints. Him toe went that way. See! [pointing to the book].

M: I see.

C: And him toe went this way.

M: Mmhm.

C: And him toe went every way. 
Page 5-6

C: And then him saw some track. But him saw a new track right there.

M: He saw a new track, huh?

Page 7-8

C: It was come from a stick. And you know what? It was time $\mathrm{xxx}$.

Page 9

C: Then a snowball fell on him head and him makin $(\mathrm{g})$ more tracks.

Page 10

C: And then big boy(s) were throwing [mother interrupts]

M: Snowballs.

C: Snowballs.

M: At him? Oh, that was fun.

C: But he want to join in, but he wasn't very big enough.

$\mathrm{M}: \mathrm{Oh}$, he was still small?

C: Uh huh. I think we missed that page [Child skips a page but turns back.]

Page 11-12

C: And him make a happy snowman.

$\mathrm{M}: \mathrm{Oh}$.

C: And him make a snowman too [corrects herself], a snow angel.

M: A snow angel. That's right.

Page 13-14

C: And him climb up a big mountain and then him slide down [Mom laughs].

Page 15-16

C: But then him roll his snowball up and then $\mathrm{xxx}$. And then him put in him pocket. And then take off him dirty socks. [Corrects herself.] Him mom take off him dirty socks.

Page 17

C: And (he) taking a bath.

M: Gave him a bath.

Page 18

C: And before him went to bed him look and he see a snowball was in his pocket but they were all gone. Snow cannot just stay in your pocket. They need cold. M: Right.
C: To help them.

M: That's right. What happens ... [Restarts] What is it the snow turns into when it melts?

C: Melt, melt, melt.

M: But when it melts what does the snow turn to? Do you remember? Remember we filled the cup with water and then we put it in the freezer.

C: Ice.

M: Ice. So when ice and snow melts what does it turn into?

C: Warm.

M: When it gets warm what does it turn into? Do you remember? [Waits for child to answer then moves on once she sees the child does not remember] Not really.

C: Unh unh.

Page 19-20

C: And him thinkin(g) about (how it) won't be there [Mom interrupts]

M: Right.

$\mathrm{C}$ : In the morning.

$\mathrm{M}: \mathrm{Mmhm}$. Because the sun melts it. And it turns back to water.

Page21

C: That's all of Snowy Day. And him call out him friends and him went to play with them.

M: Good job!

C: The end.

\section{References}

[1] S. M. Curenton, L. M. Justice, T. A. Zucker, and A. McGinty, "Language and literacy curriculum and instruction," in Response to Intervention in Early Childhood, B. Virginia and P. F. Ellen, Eds., pp. 237-249, Brookes, Baltimore, Md, USA, 2013.

[2] G. H. Brody, D. L. Flor, and N. M. Gibson, "Linking maternal efficacy beliefs, developmental goals, parenting practices, and child competence in rural single-parent African American families," Child Development, vol. 70, no. 5, pp. 1197-1208, 1999.

[3] G. H. Brody, Z. Stoneman, and J. K. McCoy, "Contributions of protective and risk factors to literacy and socioemotional competency in former head start children attending kindergarten," Early Childhood Research Quarterly, vol. 9, no. 3-4, pp. 407-425, 1994.

[4] E. Sulzby, “Children's emergent reading of favorite storybooks: A Developmental Study," Reading Research Quarterly, vol. 20, no. 4, pp. 458-481, 1985.

[5] E. Sulzby, C. M. Branz, and R. Buhle, "Repeated reading of literature and low socioeconomic status black kindergartners and first graders," Reading \& Writing Quarterly, vol. 9, no. 2, pp. 183-196, 1993.

[6] E. Sulzby and W. H. Teale, "Young children's storybook reading: longitudinal study of parent-child interaction and children's independent functioning," Final Report to the Spencer Foundation, University of Michigan, Ann Arbor, Mich, USA, 1987. 
[7] L. C. Taylor, J. D. Clayton, and S. J. Rowley, "Academic socialization: understanding parental influences on children's schoolrelated development in the early years," Review of General Psychology, vol. 8, no. 3, pp. 163-178, 2004.

[8] J. N. Kaderavek and E. Sulzby, "Narrative production by children with and without specific language impairment: oral narratives and emergent readings," Journal of Speech, Language, and Hearing Research, vol. 43, no. 1, pp. 34-49, 2000.

[9] S. M. Curenton and L. M. Justice, "Children's preliteracy skills: Influence of mothers' education and beliefs about sharedreading interactions," Early Education and Development, vol. 19, no. 2, pp. 261-283, 2008.

[10] R. Lever and M. Sénéchal, "Discussing stories: on how a dialogic reading intervention improves kindergartnersoral narrative construction," Journal of Experimental Child Psychology, vol. 108, no. 1, pp. 1-24, 2011.

[11] C. J. Lonigan and G. J. Whitehurst, "Relative efficacy of parent and teacher involvement in a shared-reading intervention for preschool children from low-income backgrounds," Early Childhood Research Quarterly, vol. 13, no. 2, pp. 263-290, 1998.

[12] C. J. Lonigan, J. L. Anthony, B. G. Bloomfield, S. M. Dyer, and C. S. Samwel, "Effects of two shared-reading interventions on emergent literacy skills of at-risk preschoolers," Journal of Early Intervention, vol. 22, no. 4, pp. 306-322, 1999.

[13] S. M. Curenton, M. J. Craig, and N. Flanigan, "Use of decontextualized talk across story contexts: how oral storytelling and emergent reading can scaffold children's development," Early Education and Development, vol. 19, no. 1, pp. 161-187, 2008.

[14] S. Martin-Chang and O. Gould, "Reading to children and listening to children read: mother-child interactions as a function of principal reader," Early Education and Development, vol. 23, no. 6, pp. 855-876, 2012.

[15] S. M. Curenton, Mother-Child Reading Interactions in FirstGrade, University of Virginia, 2002.

[16] E. J. Keats, The Snowy Day, Penguin, New York, NY, USA, 1962.

[17] L. M. Dunn and L. M. Dunn, Examiner's Manual for the PPVTIII Peabody Picture Vocabulary Test, AGS, 1997.

[18] G. S. Wilkinson, WRAT-3: Wide Range Achievement Test Administration Manual, Wide Range, Wilmington, Del, USA, 1993.

[19] R. H. Bradley, L. Whiteside-Mansell, J. A. Brisby, and B. M. Caldwell, "Parents' socioemotional investment in children," Journal of Marriage and Family, vol. 59, no. 1, pp. 77-90, 1997.

[20] J. Brooks-Gunn, G. J. Duncan, and N. Maritato, "Poor families, poor outcomes: the well-being of children and youth," in Consequences of Growing Up Poor, pp. 1-17, Russell Sage Foundation, 1997.

[21] NICHD Early Child Care Research Network, "Before head start: income and ethnicity, family characteristics, child care experiences, and child development," Early Education and Development, vol. 12, no. 4, pp. 545-576, 2001.

[22] E. J. Keats, Peter's Chair, Penguin, New York, NY, USA, 1967.

[23] D. K. Dickinson and P. O. Tabors, "Early literacy: linkages between home, school and literacy achievement at age five," Journal of Research in Childhood Education, vol. 6, no. 1, pp. 3046, 1991.

[24] E. Reese and A. Cox, "Quality of adult book reading affects children's emergent literacy skills," Developmental Psychology, vol. 35, no. 1, pp. 20-28, 1999.

[25] C. E. Snow, P. O. Tabors, P. A. Nicholson, and B. F. Kurland, "SHELL: oral language and early literacy skills in kindergarten and first-grade children," Journal of Research in Childhood Education, vol. 10, no. 1, pp. 37-48, 1995.

[26] B. MacWhinney, The CHILDES Project: Tools for Analyzing Talk, Erlbaum, Hillsdale, NJ, USA, 2nd edition, 1994.

[27] L. Morgan and H. Goldstein, "Teaching mothers of low socioeconomic status to use decontextualized language during storybook reading," Journal of Early Intervention, vol. 26, no. 4, pp. 235-252, 2004.

[28] W. Loban, Language Development: Kindergarten Through Grade Twelve, NCTE Committee on Research Report No. 18, National Council of Teachers, 1976.

[29] S. M. Curenton and T. M. Lucas, "Assessing young children's oral narrative skills: the story pyramid framework," in Assessment in Emergent and Early Literacy, K. Pence and L. M. Justice, Eds., pp. 377-427, Brookes, Baltimore, Md, USA, 2007.

[30] K. D. Reid, W. P. Hresko, and D. D. Hammill, Test of Early Reading Ability, (TERA-3), Pro-Ed, Austin, Tex, USA, 2001.

[31] C. Elster, "Patterns within preschoolers' emergent readings," Reading Research Quarterly, vol. 29, no. 4, pp. 402-418, 1994.

[32] C. Elster, "Importations in preschoolers emergent literacy," Journal of Literacy Research, vol. 27, pp. 65-84, 1995.

[33] S. W. Valencia and E. Sulzby, "Assessment of emergent literacy: storybook reading," The Reading Teacher, vol. 44, no. 7, pp. 498500, 1991.

[34] S. M. Curenton, "The association between narratives and theory of mind for low-income preschoolers," Early Education and Development, vol. 15, no. 2, pp. 124-146, 2004.

[35] B. Hart and T. R. Risley, Meaningful Differences in the Everyday Experience of Young American Children, Brookes, Baltimore, Md, USA, 1995.

[36] S. B. Heath, Ways With Words: Language, Life and Work in Communities and Classrooms, Cambridge university Press, Boston, Mass, USA, 1983.

[37] C. S. Hammer and A. L. Weiss, "African American Mothers' views of their infants' language development and languagelearning environment," American Journal of Speech-Language Pathology, vol. 9, no. 2, pp. 126-140, 2000. 

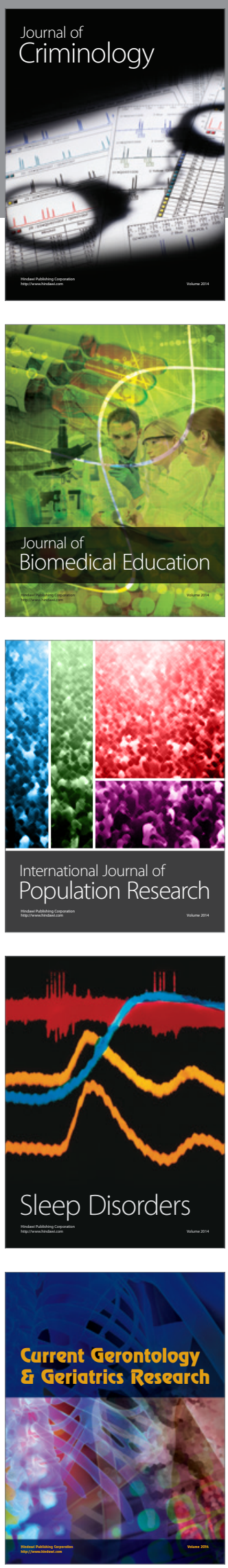
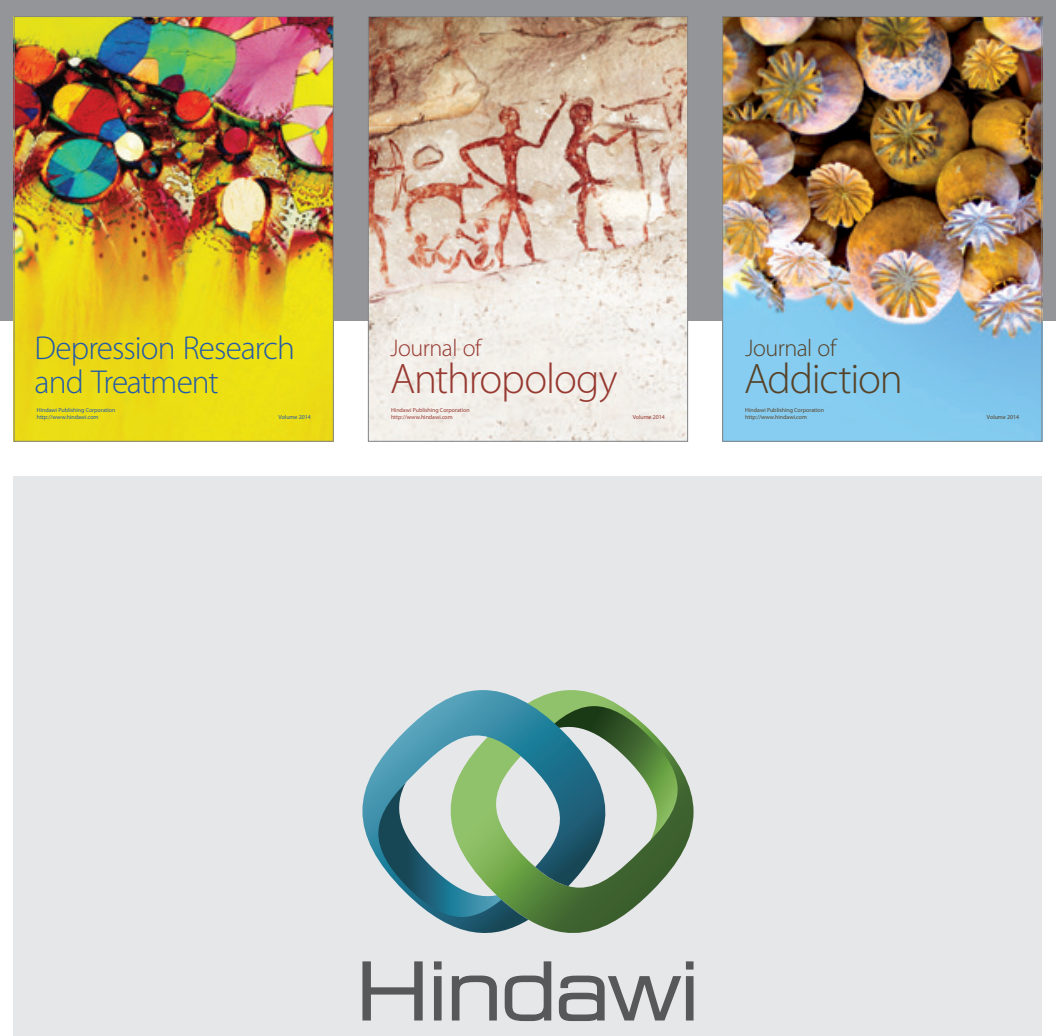

Submit your manuscripts at

http://www.hindawi.com

Child Development Research
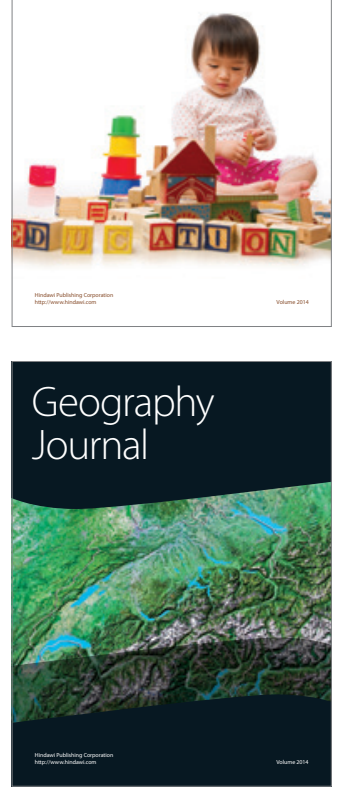

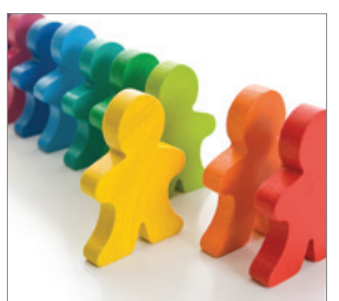

Autism

Research and Treatment
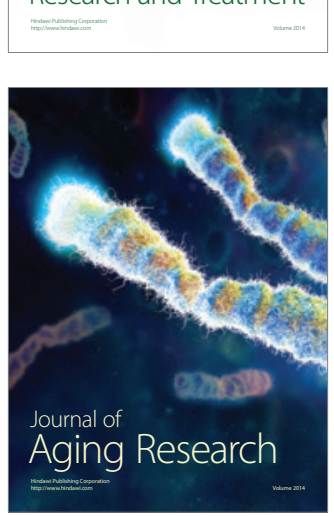
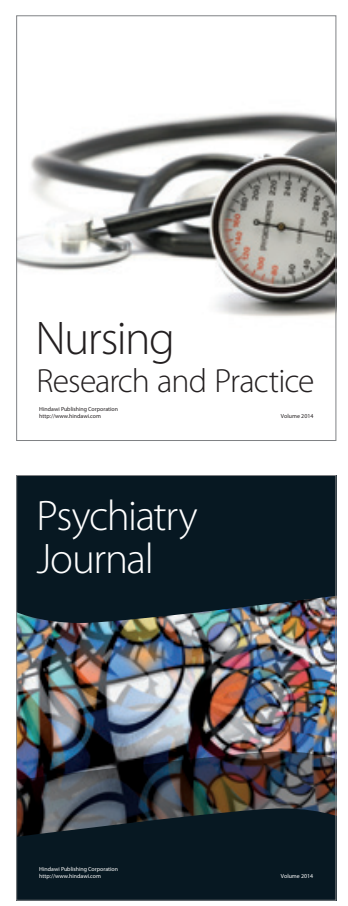
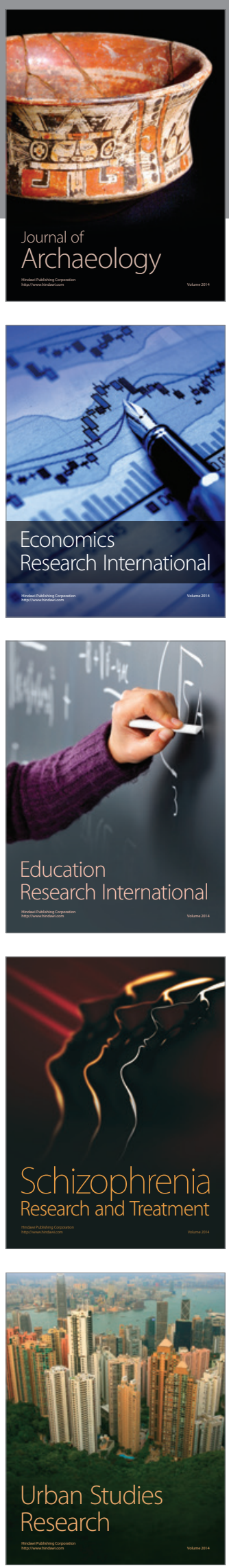